\title{
A "neglected part of the curriculum" or "of limited use"? Views on genetics training by nongenetics medical trainees and implications for delivery
}

Sarah Burke, BA, MA ${ }^{1}$, Anna Stone, MRCGP, MRCP ${ }^{2}$, Julie Bedward, BSoc Sc, PGCE ${ }^{3}$, Hywel Thomas, $P h D, M E d^{4}$, and Peter Farndon, $M S c, M D^{5}$

\begin{abstract}
Purpose: Although the importance of genetics education for health care professionals is increasingly recognized worldwide, little is known about the needs and views of nongenetics postgraduate medical trainees. Methods: Data on the views of 143 learners from four specialties (family practice, neurology, cardiology, and dermatology) in two regions in England (West Midlands and South Western) were collected using focus groups, questionnaires, and interviews. Results: Low levels of genetics training were reported by both trainee family practitioners and trainee hospital consultant specialists. Responses to attitude statements indicate that the majority of trainee family practitioners believed genetics was important but thought that they were underprepared in this area. Focus groups with specialty trainees revealed general consensus that there was not enough formal postgraduate genetics training, although some cardiologists disagreed and trainees in all three specialties thought that the existing curriculum was overcrowded. Trainees stressed the importance of tailoring genetics education to be directly relevant to their daily practice. Trainee family practitioners prioritized topics related to the identification and referral of patients, and the subsequent implication of results. In contrast, specialty trainees prioritized topics related to the genetics and management of particular diseases. Conclusion: There is still work to be done before trainees in nongenetics specialties recognize how genetics can be relevant to their practice. Involvement of specialty trainers in the development and delivery of genetics education may help to address this issue. Genet Med 2006:8(2):109-115.
\end{abstract}

Key Words: genetics education, educational strategies, needs analysis, family practitioners, specialist trainees

The importance of genetics education for health care professionals is increasingly recognized worldwide. ${ }^{1-4}$ Developments in genetics and genetic technologies are expected to have a widespread impact on health professionals as genetic specialists are unlikely to be able to meet increased patient demand in the future. ${ }^{5-8}$ The "invasion" of genetics into mainstream medical practice ${ }^{9}$ has not been universally welcomed, ${ }^{5,10,11}$ and there is concern that health care professionals are not currently adequately prepared for this extended role and will require additional education if they are to meet this need.2,12-14

In the United Kingdom, the genetics White Paper published in $2003^{15}$ included a commitment to education and training

From the ${ }^{1}$ Centre for Research in Medical and Dental Education, University of Birmingham; ${ }^{2}$ Partner Thornley Street Surgery and GPwSI in Genetics, Wolverhampton Primary Care Trust, Wolverhampton, United Kingdom; ${ }^{3}$ Centre for Research in Medical and Dental Education, University of Birmingham; ${ }^{4}$ Centre for Research in Medical and Dental Education, University of Birmingham; ${ }^{5}$ NHS National Genetics Education and Development Centre, Birmingham, United Kingdom.

Sarah Burke, Centre for Research in Medical and Dental Education, School of Education, The University of Birmingham, Edgbaston, Birmingham, B15 2TT, UK.

Submitted for publication July 12, 2005.

Accepted for publication November 14, 2005.

DOI: 10.1097/01.gim.0000200159.19920.b5 for health care staff. It also announced plans for an NHS Genetics Education and Development Centre, which was established in 2004. ${ }^{15,16}$ Before this, research had been conducted to review current education ${ }^{17}$ and develop genetic competencies ${ }^{4,18-20}$ in a range of contexts. However, little research has focused on the needs of medical trainees engaged in training for specialist status or has explored their views of genetics education.

Because information on learners' needs and attitudes is important for the development of effective postgraduate training, ${ }^{2,21}$ two complementary studies were undertaken in the United Kingdom by the Centre for Research in Medical and Dental Education at the University of Birmingham in collaboration with the Centre for Education in Medical Genetics at the West Midlands Regional Genetics Service.

The studies were designed to explore trainees' experiences of genetics education provision in their undergraduate and postgraduate training and their awareness of genetics issues in their current clinical work. Trainees were also asked to identify what they considered to be the most important topics for postgraduate training in genetics and their preferred method of educational delivery. 
The first study involved trainee hospital consultant specialists (specialist registrars) in cardiology, dermatology, and neurology in the West Midlands and South Western regions of England. These specialties were chosen because they provide a contrast in terms of the perceived current clinical utility of genetics: its role in patient management is well established in neurology and increasingly being recognized in dermatology, but is considered in cardiology to make a minimal contribution to the majority of patient care. The West Midlands and South Western regions were chosen to determine whether the views of the trainees were influenced by their geographic setting: the West Midlands is mostly an industrial conurbation with a high density of population and hospitals, whereas the South Western region is mostly rural with hospital training centers in widely dispersed towns.

The second study focused on specialist training for primary care, exploring the views of trainee family practitioners (general practice registrars) within the West Midlands region. Family practitioners have been signposted as playing an important role in identifying families who might benefit from genetic advances. ${ }^{8}$ However, research suggests that family practitioners currently have relatively limited knowledge of genetics and low levels of confidence in this area. ${ }^{5,13,22}$

\section{A brief overview of training in medicine in the United Kingdom}

In the United Kingdom, initial training in medicine is through an undergraduate course at medical school, which normally lasts 5 years, followed by postgraduate training. The training period immediately after medical school is currently undergoing radical change with the introduction of a Foundation Programme leading to specialist and general practice training. ${ }^{23}$ However, at the time of the study doctors who had completed their undergraduate medical degree spent 1 year working as a preregistration house officer in a hospital before being granted full registration with the General Medical Council. They were then required to complete basic specialist training as a Senior House Officer before entering either Higher Specialist Training as a Specialist Registrar to become a specialist consultant (usually in hospital) or General Practice training as a General Practice Registrar. General practitioners (GPs) provide preventive and treatment services through a familybased primary care service throughout the United Kingdom and refer families to hospital and other services as appropriate.

Postgraduate medical education is delivered regionally. Medical and surgical specialties currently have nationally agreed curricula, but general practice does not, although a curriculum for general practice training is currently being developed by the Royal College of General Practitioners. ${ }^{24}$ In the undergraduate training there is currently no nationally agreed curriculum for genetics education, although a list of core genetics topics agreed by the Joint Committee on Medical Genetics and the British Society of Human Genetics is now being reviewed by the NHS National Genetics Education and Development Centre..$^{25}$

\section{METHODS}

For cardiology, dermatology, and neurology, six groups of trainees were consulted (one group from each of the three specialties in both regions) between January and March 2003. The total sample was 53 ; 33 of $54(61 \%)$ specialist trainees in the three specialities in the West Midlands and 20 of 27 (74\%) in the South Western region. All years of experience from year 1 to year 6 were represented. Five groups were consulted at focus group meetings during training events, with permission from local training organizers. Trainees were asked to complete an anonymous questionnaire about their experiences of genetics education and then to participate in focus group discussions about genetics and genetic education. Neurology trainees in the South West were consulted through individual telephone interviews because it was not possible to arrange a group meeting, reflecting their geographic dispersal in a rural region. Members of the research team took notes of responses, which were read back to the group or individual for verification and later analyzed thematically. All group members were encouraged to contribute, and differences in opinion between group members were recorded. National curriculum documents for cardiology, dermatology, and neurology were reviewed for genetics content.

It was intended that a similar methodology be used to consult trainee family practitioners in the West Midlands, but direct access to group meetings was declined by training organizers. A postal questionnaire was therefore devised using the same questions that trainee specialists completed at the beginning of the focus groups and extended to include questions and attitude statements that had been explored in the focus groups. Although group discussion of issues could not take place, the questionnaire allowed consultation with a larger group. All 123 trainee family practitioner trainees in four areas of the West Midlands (South Birmingham, North/West Birmingham, Black Country, and Coventry and Warwickshire) were sent a postal questionnaire in June 2003, with a re-mail to nonrespondents in July 2003. Ninety anonymous responses were received, a response rate of $73 \%$.

Both questionnaires were developed by the research team and included open and closed questions. Responses to open questions were coded thematically by members of the research team. Items in the questionnaires and focus group topics are described with the respective results in the next section.

\section{RESULTS}

\section{Experiences of genetics education in undergraduate and postgraduate training}

To gather information about previous exposure to genetics, the questionnaires invited trainees through open responses to list the genetic topics they could remember being taught in their undergraduate and postgraduate training and to estimate the amount of time devoted to genetics.

The genetics topics recalled as having been taught in their undergraduate medical courses were the same for both special- 
ist and family practitioner trainees, which suggested that both groups entered postgraduate training with similar experiences of genetics topics. The most commonly cited topics were modes of inheritance, common genetic disorders (including single gene and chromosomal), and basic scientific principles.

However, there was a difference in recall of the amount of time devoted to genetics. Teaching had most usually been through a series of lectures; $73 \%$ of specialist trainees and $40 \%$ of trainee family practitioners reported between 1 day and 1 week of undergraduate training in genetics. Six trainee family practitioners ( $7 \%$ of respondents to that question) could not recall any time having been allocated to genetics in their undergraduate training, although comments included that it was a "long way back to remember." A further 12 reported either "very little" or only a few hours of genetics training. It was reported that the clinical aspects of genetics had not always been to the fore in the undergraduate courses, genetics most often having been presented as a purely scientific subject.

With regard to postgraduate training, a majority of trainee family practitioners $(85 \%)$ indicated that genetics sessions had not been timetabled within their family practitioner training; $12 \%$ reported receiving "very little" or a few hours of training. Five respondents identified that genetics issues did arise during case discussions, most commonly relating to cancer, but $78 \%$ of trainee family practitioners indicated that they could not recall covering any genetics topics so far.

The situation in specialist training was similar. Approximately half $(46 \%)$ of respondents reported that genetics had not been timetabled in their specialist training to date, and a further 30\% indicated that less than 1 day's training had been provided. Time devoted to genetics was particularly low in cardiology, in which $4 \%$ of respondents reported more than 2 days of training (compared with 21\% in dermatology and 29\% in neurology). Genetics topics were discussed in training when these arose as part of diagnosis and management of particular disorders ( $58 \%$ of respondents in cardiology, $45 \%$ overall), but $45 \%$ could not recall covering genetics topics during their specialist training. This could not be explained wholly by the year of study of the trainee: thirty-two percent of respondents from years 2 to 6 stated that they had covered no genetics topics during their higher specialist training (compared with $62 \%$ in year 1). The focus group discussions confirmed that trainee specialists who considered themselves to have more experience in genetics than their peers were often self-taught, most having read up on conditions that had presented in the clinic.

This reported experience may mirror the expectations for genetics education within the training programs as found through our review of published curricula. At the time of the study the curricula for dermatology and cardiology contained little genetics content. The cardiology curriculum required that trainees become "conversant with the genetics and prenatal diagnosis of congenital heart disease," whereas the dermatology curriculum stated that trainees should acquire basic knowledge of genetics and genetic counseling. Genetics had a more visible presence in the neurology curriculum, with neurogenetics identified as an important component of the training and the knowledge, clinical skills, and attitudes required listed in some detail. The three curricula have recently been revised and the genetic content in all three has increased, although it remains most prominent in the neurology curriculum.

\section{Views on the frequency of genetic issues in clinical cases}

The questionnaires asked trainees to indicate how often they thought genetics presented as an element of a case: at least once per day, at least once per week, at least once per month, or only rarely. Approximately half of trainee family practitioners (49\%) indicated that genetics presents as an element of a case only rarely; $6 \%$ believed it presented every day. Among the specialist trainees differences by specialty were evident, confirming the perceived clinical utility of genetics as discussed in the introduction. For cardiology trainees approximately half (46\%) reported encountering genetics only rarely with $13 \%$ suggesting it formed part of a case daily. In dermatology fairly equal proportions reported encountering cases daily, weekly, monthly, and only rarely. In contrast, most neurology trainees $(63 \%)$ reported genetics elements presenting in their cases at least once per week.

\section{Views on whether genetics education is important}

The questionnaire asked trainee family practitioners to indicate the degree to which they agreed or disagreed with a series of statements on a five-point scale (strongly agree, agree, disagree, strongly agree, don't know). The results, shown in Table 1 , indicate that genetics was viewed as an important subject, even though approximately half of trainee family practitioners

Table 1

General practitioners' views on genetics

\begin{tabular}{|c|c|c|c|c|c|}
\hline Statement & $\begin{array}{l}\text { Strongly agree } \\
(\%)\end{array}$ & $\begin{array}{l}\text { Agree } \\
(\%)\end{array}$ & $\begin{array}{l}\text { Disagree } \\
(\%)\end{array}$ & $\begin{array}{l}\text { Strongly disagree } \\
(\%)\end{array}$ & $\begin{array}{l}\text { Don't know } \\
(\%)\end{array}$ \\
\hline Learning about genetics is not a productive use of my time & $0(0)$ & $3(3)$ & $67(74)$ & $16(18)$ & $4(4)$ \\
\hline $\begin{array}{l}\text { Genetics is increasingly important and must be given more } \\
\text { attention in my training }\end{array}$ & $9(10)$ & $72(80)$ & $6(7)$ & $0(0)$ & $3(3)$ \\
\hline I feel I know all I need to know about genetics for my job & $0(0)$ & $9(10)$ & $53(59)$ & $22(24)$ & $6(7)$ \\
\hline $\begin{array}{l}\text { The training that I have received in genetics has been sufficient } \\
\text { to prepare me for work as a general practitioner }\end{array}$ & $0(0)$ & $17(19)$ & $49(54)$ & $15(17)$ & $9(10)$ \\
\hline
\end{tabular}


had identified that genetics presented only rarely as an element of a case. The large majority (92\%) disagreed or strongly disagreed with the statement "learning about genetics is not a productive use of my time," and 90\% agreed or strongly agreed that "genetics is increasingly important and must be given more attention in my training." However, the results also suggest that the trainees felt underprepared in this area. Only $10 \%$ of respondents agreed with the statement "I feel I know all I need to know about genetics for my job," and $71 \%$ disagreed or strongly disagreed with the statement "the training that I have received in genetics has been sufficient to prepare me for work as a GP." In addition, when asked to list the services they were aware of in the region to give advice on genetic cases, $41 \%$ of respondents wrote "none" or "not sure."

Of 33 trainee family practitioner respondents who gave written comments, 15 (45\%) stated that they needed to know more about genetics, one saying: "Better education is vital before patients teach/correct us." Twelve respondents (36\%) emphasized the importance of training in genetics, a growing patient demand, and the potential role of genetics in preventative medicine. Five (15\%) stated that little attention is currently given to genetics within their training, one describing it as "a neglected part of the curriculum," and three noted that trainers know little about genetics. In contrast, five trainees (15\%) suggested that there were more important topics to learn about during their family practitioner training, describing it as "of limited use" and "not high on my list of priorities."

Data on trainee specialists' views were collected through focus group discussions. First, they were asked to consider whether current genetics training was sufficient. All discussion groups thought that their training in genetics at the undergraduate level had been adequate but that there was not enough genetics training at the postgraduate level. Reasons cited included the knowledge gained at medical school had since been forgotten; the knowledge was now out of date; and they now needed more in-depth knowledge as trainee specialists. However, this view was not universally accepted. Some cardiology trainees said that they did not need to know much about genetics for their daily clinical practice and that the basic knowledge gained at medical school was sufficient. One trainee suggested that conditions with genetic implications were simply referred to a specialist; another said, "I don't feel that genetics training would make us better cardiologists." Other cardiology trainees disagreed, arguing that more training would raise their awareness of the relevance of genetics to their practice and their learning needs. Even among those groups who recognized a need for more postgraduate genetics training, there was recognition that a barrier to such training was an overcrowded curriculum, an issue raised in all three specialties. Trainees referred to "competing priorities for time," arguing that an increase in genetics training would mean less time for other subjects.

\section{Preferred forms of educational delivery}

Views on educational delivery did not seem to be affected by trainees' location in a rural or urban setting. In the neurology and dermatology groups there was consensus that genetics should be recognized as a subject for training in its own right. Formal, didactic genetics training should occur once per year with either a day or half-day set aside within regional training programs. They thought this formal teaching should be supplemented by other learning, either through formal training days about specific conditions with a genetic element or informal "on-the-job" learning as conditions present in clinics. In cardiology the consensus view was that formal genetics training of half a day once in the training period would be sufficient. However, some thought that a "genetics day" would put them off and stated that they would prefer genetics training to be provided through an integrated approach, with brief genetics components (of 15 to 30 minutes) added to teaching on specific conditions throughout the course. Within family practitioner training, the majority (74\%) indicated that there should be at least 1 day devoted to genetics, whereas a further $25 \%$ suggested half a day would be sufficient.

The most popular format for genetics education was faceto-face teaching, preferred by $45 \%$ of trainee family practitioners and the majority of specialist trainee focus group participants. Several focus group participants and 39\% of trainee family practitioner respondents suggested that formal teaching be supported by written or electronic reference materials.

Specialist trainees commented that a major benefit of faceto-face teaching was that it could take place within regional training days, which formed protected learning time away from clinics. This was seen as a major advantage over selfdirected learning, which would occur within personal time and was therefore considered less likely to take place. However, some did express a preference for self-directed learning, such as reading up on conditions encountered in clinics, because this learning was relevant to daily practice. Many also said they would prefer training to be focused on the common inherited conditions within their own specialty and on the practical applications of how to manage patients with genetic disorders.

In terms of who should provide genetics training, there was general consensus among the trainee specialists that education would ideally be delivered by either a clinical geneticist with a special interest in the specialty or a specialty consultant with a special interest in genetics, although some acknowledged the difficulty of achieving this. A need was stressed for up-to-date information, presented at a level they could understand, which was highly relevant to their daily clinical practice. Among trainee family practitioners the most popular option, raised by $41 \%$ of questionnaire respondents, was for genetics training to be provided by a team of a geneticist and GP trainer (delivery by a geneticist was the second most popular, identified by $33 \%)$. Again the importance of presenting in-depth, up-todate information in the context of practical application to the specialty was stressed.

Trainees' views were also sought regarding learning with other professional groups. The questionnaire asked trainee family practitioners whether there were any other professional groups with whom it would be productive to learn about genetics. A quarter of respondents thought that learning with 
geneticists or genetics counselors would be appropriate, and $13 \%$ thought it would be appropriate to learn with nurses, although a further $13 \%$ responded "no," one writing "Information about genetics should be tailored to our needs as GPs." Specialist trainees were against learning with other professionals. The majority stated strongly that learning should not take place across specialties because they believed teaching should be focused on their needs and relevant to their practice, one saying: "I need the teaching to be relevant to the specialty, relevant to the cases I see in clinics." These groups also expressed a strong preference for learning with other trainee specialists rather than with other professional groups, again stressing the need for education to be focused on their particular needs. One said: "Different team members have different roles, so you need to teach according to those roles, not across them."

\section{Topics considered by trainees to be the most important for inclusion in genetics training}

Trainees were asked to identify genetics topics they thought should be covered within their specialist training.

The trainee family practitioner survey listed genetics topics (which had previously been generated by a group of $40 \mathrm{GP}$ trainers, 10 training organizers, and 10 geneticists from the West Midlands) and asked respondents to indicate how important they thought each was: "not useful for my work"; "useful but not essential"; "essential”; or "don't know." They were also asked when each topic should be taught: in undergraduate or postgraduate training, or both. Table 2 summarizes those rated "essential" and considered appropriate during family practitioner training by more than $50 \%$ of respondents. The basic science of genetics was considered essential by $72 \%$ of respondents, a further $28 \%$ rating it "useful but not essential." However, $77 \%$ of respondents believed that this topic should only be taught at the undergraduate level, and therefore "basic science of genetics" is not listed in Table 2 for trainee family practitioners.
Focus groups with trainee specialists included a group exercise in which they were asked to suggest genetics topics and indicate when they should be taught (undergraduate, specialist training, or both). A number of specialty-specific topics were identified, but those raised by more than one specialty group and considered suitable for specialist training by the majority of the group are listed in Table 2.

Knowledge of patterns of inheritance was also identified as a cross-specialty topic, but the majority of trainee specialists thought that it was best covered only at the undergraduate level. Unlike the trainee family practitioners, the majority of specialist trainees thought that basic genetic science should be covered at both the undergraduate and specialist training levels, many stating that they would like to revise the basic concepts before moving on to more complex subjects.

The lists of topics, perceived as important and useful by the trainees, offer an insight into the different perspectives of family and hospital-based practice. Trainee family practitioners are concerned about identifying families at highest risk of genetic disorders and referring them appropriately. They are concerned about the ethical implications of genetic screening and testing and want to know how genetics will help people with the most common forms of disease, cancer, and multifactorial conditions. Trainee specialists were understandably more concerned about acquiring detailed knowledge of genetics relating to the conditions they encounter in their specialty. It was interesting to hear that the potential promise of gene therapy as presented in the media was reflected in a desire among specialist trainees to know how (and when) this would be applicable for their specialties; gene therapy was viewed as a tangible sign that genetics could have therapeutic utility.

\section{Points to consider in the provision of genetics education}

Table 3 lists key points that have emerged from our studies that may be helpful in informing the planning of genetics education initiatives for postgraduate medical trainees.

Table 2

Genetics topics identified as most important by trainees

Topics identified by trainee family practitioners

Taking and interpreting a family history

Appropriate referral to genetics services

Common single gene and chromosomal conditions

Multifactorial conditions

Cancer genetics

Screening for genetic conditions

Social and psychological implications for family and patient

Ethical, philosophical, and cultural perspectives

Legal issues (particularly insurance)

How to access further information
Topics identified by trainee specialists (in cardiology, dermatology, neurology)

Basic genetic science

Knowledge of common genetic conditions (appropriate for specialty)

Knowledge of databases

Gene therapy

Genetic screening

How to access services

When to refer to a geneticist

What happens in the genetics laboratory 
Table 3

Key points to inform the planning of genetics education initiatives

Many trainee hospital specialists do not yet view genetics as relevant to their current clinical work.

Views on the importance of genetics are influenced by the amount of genetics in specialty curricula and by trainers.

Trainees want genetics education to focus on common clinical conditions within their own specialty and be directly relevant to patient care.

There is a strong preference for face-to-face teaching in small group tutorials, delivered by trainers with expertise in genetics.

Educational materials should be developed through partnership between the specialty and geneticists.

There is clearly a difference of opinion among trainees regarding the importance of genetics. Responses to attitude statements by trainee family practitioners indicate that they recognize the importance of genetics but feel underprepared in this area, a result supported by the inability of $41 \%$ of respondents to identify any genetic services in the region. However, open comments reveal that some individuals do not view genetics as relevant to their work, and approximately half (49\%) of respondents indicated that genetics presented as an element of a case only rarely. Among trainee specialists, the majority highlighted the need for more postgraduate genetics education. Some individual cardiology trainees did not view it as a priority area, however, possibly a product of a specialty in which genetic factors are not seen as the primary cause of the majority of conditions encountered. Approximately half of cardiology respondents $(46 \%)$ indicated that genetics presented as an element of a case only rarely. A strategy for genetics training in cardiology would therefore be to highlight disorders with a high risk to other family members of morbidity or mortality (e.g., Marfan syndrome, inherited cardiomyopathies, or arrhythmias).

A lack of awareness of the clinical utility of genetics is perhaps unsurprising given the low priorities currently afforded to genetics within specialty training. An important factor to consider is the influence of the "hidden curriculum" that is embedded in the attitudes and inflections of trainers. ${ }^{26}$ Consultants and GP trainers serve as role models to trainees, who may be influenced by the attitudes of their trainers. In focus group discussions, trainees who strongly defended the importance of genetics often referred to comments made by a trainer with an interest in the field. However, trainers may not be comfortable with recent advances in genetic science and clinical applications may have developed after their own training: open comments by three trainee family practitioners pointed out that GP trainers know little about genetics. An educational program that conflicts with the messages given in the hidden curriculum may struggle to make an impact on clinical practice, and therefore involving specialty trainers in the development and delivery of genetics education is recommended.

Trainees in all specialty groups expressed the fear that, in an already overcrowded curriculum, additional genetics training would mean education in other areas would suffer. This suggests that educational developments in genetics may be more successful if they emphasize the relevance of genetics to the day-to-day work within a particular specialty, draw on examples from that specialty, and contain practical, practice-based elements such as referral to genetics services within the local area. The preference for genetics education relevant to clinical practice is reflected in resistance to learning with other specialties or professional groups, which would necessarily be more generic. Trainees also expressed a preference for face-to-face teaching because this could occur within their protected training time. This may be another reflection of the "hidden curriculum," with trainees rating the relative importance of topics based on those that are covered in formal training.

Knowledge of learners' views of genetics will enable the development of more effective educational interventions that address the needs and concerns of learners in different specialty groups.

\section{ACKNOWLEDGMENTS}

The project exploring the genetic educational needs of nongenetics trainee specialists was funded by the Department of Health for England. The project exploring the genetic educational needs of trainee family practitioners was funded by the West Midlands Deanery.

\section{References}

1. Kirklin D. Responding to the implications of the genetics revolution for the education and training of doctors: a medical humanities approach. Med Educ 2003;37: $168-173$.

2. Metcalfe S, Hurworth R, Newstead J, Robins R. Needs assessment study of genetics education for general practitioners in Australia. Genet Med 2002;4:71-77.

3. Van Langen IM, Birnie E, Leschot NJ, Bonsel GJ et al. Genetic knowledge and counselling skills of Dutch cardiologists: sufficient for the genomics era? Eur Heart J 2003;24:560-566.

4. Jenkins J, Blitzer M, Boehm K, Feetham Z et al. Recommendations of core competencies in genetics essential for all health professionals. Genet Med 2001;3:155-159.

5. Watson EK, Shickle D, Qureshi N, Emery J et al. The 'new genetics' and primary care: GPs' views on their role and their educational needs. Fam Pract 1999;16:420 425 .

6. Reynolds PP, Beckendorf JL. Genes and generalists: why we need professionals with added competencies. West J Med 1999;171:375-379.

7. Zimmern R, Cook C. The Nuffield Trust Genetics Scenario Project. Genetics and Health: policy issues for genetic science and their implication for health and health services. London: The Nuffield Trust 2000.

8. Royal College of General Practitioners (RCGP). Genetics in primary care: a report from the RCGP North West England Faculty Genetics Group. Occasional Paper 77. 1998.

9. Collins FS, Guttmacher AE. Genetics moves into the medical mainstream. JAMA 2001;286:2322-2324.

10. Emery J, Hayflick S. The challenge of integrating genetic medicine into primary care BMJ 2001;322:1027-1030.

11. Kumar S, Gantley M. Tensions between policy makers and general practitioners in implementing the new genetics: grounded theory interview study. BMJ 1999;319: 1410-1413.

12. Lapham E, Kozma C, Weiss J, Benkendorf J et al. The gap between practice and genetics education of health professionals: HuGEM survey results. Genet Med 2000; 2:226-231. 
13. Hayflick SJ, Eiff MP. Will the learners be learned? Genet Med 2002;4:43-44.

14. Burton $\mathrm{H}$. Addressing genetics delivering health. A strategy for advancing the dissemination and application of genetics knowledge throughout our health professions. Cambridge: Public Health Genetics Unit; 2003.

15. Department of Health. Our inheritance, our future: realising the potential of genetics in the NHS. London: The Stationery Office; 2003.

16. NHS National Genetics Education and Development Centre [online]. www.geneticseducation.nhs.uk. Accessed 5 October 2005. NHS National Genetics Education and Development Centre .

17. Burton H. Education in Genetics for Health Professionals. Report to the Wellcome Trust. Cambridge: Public Health Genetics Unit; 2002.

18. Kirk M. Fit for practice in the genetics era: a competence based education framework for nurses, midwives and health visitors. Glamorgan: Genomics Policy Unit; 2003.

19. British Society for Hum Genet (BSHG). Teaching medical genetics to undergraduate medical students, 2003. www.bshg.org.uk. Accessed 22 February 2005.
20. Friedman JM, Blitzer M, Elsas LJ, Francke U et al. (Association of Professors of Hum Genet, Clinical Objectives Task Force). Clinical Objectives in medical genetics for undergraduate medical students. Genet Med 1998;1:54-55.

21. Norman GR, Shannon SI, Marrin ML. The need for needs assessment in continuing medical education. BMJ 2004;328:999-1001.

22. Emery J, Watson E, Rose P, Andermann A. A systematic review of the literature exploring the role of primary care in genetic services. Fam Pract 1999;16:426-445.

23. Donaldson L. Unfinished business: proposals for reform of the Senior House Officer Grade. London: Department of Health; 2002.

24. Royal College of General Pracititioners. GP Curriculum Consultation [online]. www.rcgp.org.uk. Accessed 5 October 2005.

25. Haites N. Teaching medical genetics to undergraduate medical students [online]. www.bshg.org.uk. Accessed 5 October 2005. British Society for Human Genetics; 2003.

26. Marinker M. Myth, paradox and the hidden curriculum. Med Educ 1997;31:293298 